Voix et Images

voixetimages

\title{
Le féminisme, une nécessité vitale
}

\section{Lori Saint-Martin}

Volume 18, numéro 2 (53), hiver 1993

Francine Noël

URI : https://id.erudit.org/iderudit/201033ar

DOI : https://doi.org/10.7202/201033ar

Aller au sommaire du numéro

\section{Éditeur(s)}

Université du Québec à Montréal

\section{ISSN}

0318-9201 (imprimé)

1705-933X (numérique)

Découvrir la revue

\section{Citer cet article}

Saint-Martin, L. (1993). Le féminisme, une nécessité vitale. Voix et Images, 18(2), 390-394. https://doi.org/10.7202/201033ar d'utilisation que vous pouvez consulter en ligne.

https://apropos.erudit.org/fr/usagers/politique-dutilisation/ 
Féminismes

\section{Le féminisme, une nécessité vitale}

Lori Saint-Martin, Université du Québec à Montréal

Avec le présent numéro, Voix et Images inaugure une nouvelle cbronique, "Féminismes, consacrée aux débats touchant l'écriture au féminin, les combats féministes, bref toutes les grandes questions que soulève un courant de pensée novateur et toujours actuel. 
L'une des idées reçues les plus absurdes de notre époque est celle qui veut que le féminisme ait été une simple mode intellectuelle. Vous avez eu votre heure de gloire dans les années soixante-dix, dit-on implicitement aux féministes; vous avez remporté vos batailles. L'égalité de l'homme et de la femme, tout le monde l'a reconnue. Vous nous lassez, à la fin, avec vos jérémiades. Pourquoi tant vous acharner?

Douce illusion que celle de la victoire définitive du féminisme, que la seule lecture du journal du matin suffit à dissiper. Les femmes ne peuvent être prêtres, tout comme les hommes ne peuvent enfanter, lit-on, sidérée, entre deux gorgées de café. Au tournant de la page (en réalité, il s'agit d'un autre jour, mais les nouvelles se suivent et se ressemblent), on contemple la photo des sept récipiendaires des Prix du Québec: sept hommes. On s'imagine à peine le scandale qui éclatera le jour (improbable) où sept femmes rafleront l'ensemble des Prix du Québec ${ }^{1}$. Autre matin, autre choc: un professeur du Séminaire de Québec donne à lire en classe la lettre de Marc Lépine, sans aucune mise en contexte, pour en faire corriger les fautes de français. Plus grave encore, des enseignants affirment qu'il faut offrir, aux élèves blasés, des textes "qu'ils sont en mesure de comprendre ". Fautil vraiment conclure que les enfants de bonne famille s'identifient au discours de Marc Lépine?

Poursuivant sa lecture, une rôtie au miel à la main, on voit défiler des statistiques sur la violence physique, la violence économique, les écarts salariaux. Et on se dit qu'elle convient tout à fait à une féministe de 1992, la célèbre devise de Zola: "Vivre indigné".

Indignée, je vis. Dans une réalité qui se transforme tantôt à une vitesse prodigieuse (entre la vie des femmes d'aujourd'hui et celle de leurs grand-mères, pas de commune mesure), tantôt à un rythme de tortue. Le féminisme comme mouvement de société est à la fois un combat, une action militante et, pour l'universitaire que je suis, une éthique de vie et un débat d'idées. C'est de ce débat, toujours actuel, hélas ${ }^{2}$ ! que rendra compte la nouvelle chronique "Féminismes ${ }^{3}$ " de Voix et Images. Il y sera question, bien entendu, de la critique au féminin, de ses visées, de ses promesses. Mais aussi de tout ce qu'englobe la question des femmes et du féminin: textes de création, vies de femmes, réflexions sur la place des femmes dans la société et dans l'histoire, sur les relations hommes-femmes et même, pourquoi pas, sur la mouvante et précaire identité masculine. 
Depuis ses débuts, la critique au féminin s'est raffinée, s'est éloignée de l'idéologie brute pour s'approcher au plus près du texte: il s'agit beaucoup moins de dénoncer les images stéréotypées de la femme véhiculées par les discours traditionnels (cette perception de la critique féministe a la vie dure) que d'étudier la spécificité de l'écriture au féminin, de découvrir de quelle façon le féminin s'inscrit dans le langage, dans la textualité. Deux récentes parutions collectives, un livre, Paroles rebelles ${ }^{4}$, et un numéro de la revue Protée, "Elle Signe ${ }^{5_{\text {, }}}$, révèlent de nouveaux aspects de la lecture au féminin.

Paroles rebelles comporte dix études consacrées à des objets très variés. Grande qualité du recueil, l'ouverture aux productions du passé, à compter de la Renaissance. Trop de critiques féministes québécoises, et pas des moindres, ont fait comme si le féminisme textuel commençait en 1970, comme si tout ce qui précède Nicole Brossard et France Théoret était frappé d'interdit. Or, pas plus que le féminisme de notre époque n'est le premier féminisme, les écrits récents ne sont pas les seuls valables du point de vue de l'écriture au féminin. Abondent, dans les études de textes du passé que contient Paroles rebelles, les bonnes surprises, voire les découvertes d'auteures peu ou pas du tout connues. On ne sait s'il faut se réjouir de la modernité de certaines âmes sœurs des siècles révolus, ou se désoler du peu d'échos et d'effets réels qu'auront eus leurs propos. Reviennent, avec les siècles, les mêmes revendications: dignité des femmes, droit aux études, participation à la vie sociale et politique.

Malgré ses qualités, le recueil souffre de ce qu'aucune théorie de l'écriture au féminin ne le sous-tend, sinon le concept de "paroles rebelles", qui n'est jamais défini avec précision, et semble bien fragile pour soutenir tout l'édifice. Les deux éléments du titre font d'ailleurs problème. Le terme "parole englobe-t-il vraiment les actions militantes (lutte pour le droit de vote, activités syndicales, fondations d'hôpitaux. ou d'écoles), où c'est bien moins le discours qui compte que les résultats concrets? Faute d'accorder au textuel une place prépondérante, nombre d'articles se démarquent mal des études sociohistoriques qui ont souvent été menées par les spécialistes des disciplines concernées. Quant au mot "rebelle", on l'applique de façon indifférenciée à toute écriture de femme:

Toute parole publique d'une femme [de la Renaissance] est rebelle (Jane Couchman)

Le terme -rebelle • en théorie politique s'applique à toute théoricienne... (Sylvie d'Augerot-Arend)

De façon générale, l'écriture de Blanche [Lamontagne-Beauregard] n'est pas révolutionnaire, mais le simple geste d'écrire et de vouloir y consacrer sa vie le devient (Lucie Lequin). 
Faute de nuances, il devient impossible, dans plusieurs textes, de distinguer entre une parole novatrice d'auteure du passé et une reprise servile d'idées reçues sur la féminité. On en arrive presque à féliciter Catherine de Médicis d'avoir ordonné le massacre de la SaintBarthélemy. En effet, quel esprit d'initiative...

Plusieurs études, surtout celles qui traitent d'un siècle d'écriture des femmes, relèvent presque du catalogue (une auteure, un paragraphe...). Manque dans ces cas un fil conducteur qui relierait les textes disparates; manque aussi parfois une mise en contexte historique. Par exemple, quand Madeleine de Scudéry écrit, au XVII siècle, que *l'amour peut aller au-delà du tombeau mais il ne va guère audelà du mariage", emprunte-t-elle à là vieille tradition de l'amour courtois, comme on pourrait le croire? Le moment serait venu, me semble-t-il, de proposer des études plus fines, mieux ciblées (comme l'excellent texte de Marie-France Silver, «1789-1793: naissance et mort du premier féminisme politique français») au lieu de se contenter de faire défiler les noms, les titres et les dates. Par exemple, Jane Couchman consacre un paragraphe aux poètes Pernette du Guillet et Louise Labé, l'une davantage *féminine * et l'autre plus contestataire; comparaison à peine esquissée mais passionnante qui, mieux développée, aurait permis de faire le point sur toute l'époque de la Renaissance, par le truchement de deux stratégies opposées, toutes deux représentatives de l'engagement des femmes en littérature.

Me semblent plus réussis les textes au sujet bien délimité (mais qui s'écartent nettement de la problématique déclarée du livre, soit «la continuelle résurgence des revendications féministes en France et au Québec "): la romancière algérienne Assia Djebär (Maïr Verthuy), la cinéaste Léa Pool (Josette Déléas). Deux textes plus généraux et fort suggestifs ferment le recueil. Dans "La douceur n'est pas encore de mise ", Marguèrite Andersen constate, non sans amertume, que tous les combats ou presque restent à mener. Le bel article de Louise Dupré, "Poésie, subversion, rébellion ", traite de la poésie récente des femmes, où l'ironie et l'anti-utopisme ont pris le pas sur la dénonciation.

Dans "Elle Signe ", beau titre où le "signe" fait office à la fois de verbe et de substantif, illustrant ainsi deux positions opposées, sont traités des sujets précis et nuancés, dont la contestation féministe de la triple contrainte (vestimentaire, sociale et linguistique) imposée aux femmes du XIX ${ }^{e}$ siècle (Christine Klein-Lataud), les stratégies d'inscription textuelle du sujet féminin autobiographique chez Christa Wolf (Barbara Havercroft), le regard, la modernité et le patriarcat tels que les révèle l'étude de deux célèbres nus féminins (Mieke Bal). Malgré la 
diversité des sujets, une belle impression d'unité se dégage du numéro: la subtilité des analyses, l'attention accordée aux fines nuances textuelles ou picturales, séduiront. Les rares déceptions l'article de Marina Yaguello qui reprend, de manière sommaire, ses recherches antérieures) ne parvienennt pas à rompre le charme.

La perfection, certes, n'est pas de ce monde, et les féministes ne sont pas des anges. Pourquoi leur en demander plus qu'on en demande aux autres? Reste que ces deux ensembles de textes soulevent des questions nouvelles, font avancer la réflexion, illustrent une fois de plus, si besoin était, la nécessité vitale - et la vitalité - de la lecture au féminin.

1. Il y a quelques années, il s'est trouvé un journaliste du Devoir pour s'indigner de ce que le prix Robert-Cliche avait été remporté, trois fois de suite, par une femme.

2. On reproche aux féministes leur discours immobile; mais les injustices qu'elles dénoncent le sont encore davantage.

3. De même qu'on commence à parler des écritures au féminin, il me semble utile de parler des féminismes.

4. Marguerite Andersen et Christine Klein-Lataud (directrices), Paroles rebelles, Montréal, Editions du Remue-ménage, 1992.

5. Elle Signe, dossier sous la responsabilité de Christine Klein-Lataud et d'Agnès Whitfield, Protée, vol. XX, n 3, automne 1992. 